\title{
Trends of Indoor Environment and Energy Consumption Incidence by Human Activities
}

\author{
Mohamed Refaee and Hasim Altan
}

\begin{abstract}
This study has been undertaken as part of the Energy Innovation for Deprived Communities (EIDC) project, which aims to deliver a new approach to energy efficiency and renewable energy projects within a minimum of ten of the most deprived communities across six Local Authorities within Yorkshire and the Humber region in the UK. The properties will be assessed by energy efficiency experts and then brought up to modern standards with a range of measures including so-called smart electricity meters and heating systems upgrades to boilers, wall and loft insulations, double glazing, insulated cladding and even solar panels where appropriate. It is important for the success of the EIDC project that both detailed monitoring and post occupancy evaluation are performed on a sample of houses before rolling out a wider refurbishment. Energy consumption and indoor environment were analysed based on indoor activity of participants. The results from one dwelling showed that the energy consumption rises in the evening due to the use of cooker to prepare dinner and the use of electric shower. In addition, the temperatures increased in the evening for everyday and remained on that level till late night due the lack of ventilation during the time. Electrical energy consumption was correlated to the indoor environment and indoor air quality. The results showed that electrical energy has a direct proportion to indoor air temperature levels i.e. temperature increases when electrical energy consumption increases.
\end{abstract}

Index Terms-Electrical Energy Consumption, Energy Efficiency, Indoor Air Quality, Indoor Environment, Indoor Activity

\section{INTRODUCTION}

$\mathrm{T}$ ime passes, things change people change and places change. Time can be felt through the sunrise and sunset, clocks and watches. When time series data is visualised, the goal is to see what has passed, what is different and what is the same, and by how much. Compared to a certain moment of time, is there more or less? What are possible explanations for the increase, decrease, or no change? Is there a recurring pattern? Expected or Unexpected?.

In order to analyse the pattern of energy consumption and indoor environment, a log sheet of indoor activity and the

Manuscript received August 1, 2013.

M. Refaee is with the Building Environments Analysis Unit (BEAU) Research Centre at the University of Sheffield, Sheffield, S1 4DP UK (e-mail: m.refaee@sheffield.ac.uk).

H. Altan is with the Building Environments Analysis Unit (BEAU) Research Centre at the University of Sheffield, Sheffield, S1 4DP UK (corresponding author phone: +44-114-2220375; fax: +44-114-2220315; email: h.altan@sheffield.ac.uk) (e-mail: hasim.altan@gmail.com). number of occupants involved in each activity is needed to help visualising the time series data recorded over the period of time.

Activity patterns of Californians were used in order to improve the accuracy of exposure assessments for air pollutants. A questionnaire was developed which consists of 24 hours recall diary of detailed activities, locations and proximity to environmental tobacco smoke (ETS), questions related to the use of or proximity to potential pollutant sources, such as consumer products and gas appliances, questions regarding housing characteristics and the ventilation habits of the respondent's household, and routine questions on socioeconomic and demographic factors. Results are presented regarding time spent by Californians' different activities and locations relevant to pollutant exposure, and their frequency of use of or proximity to pollutant sources including cigarettes, consumer products such as paints and deodorisers, combustion appliances and motor vehicles. The results show that Californians spend, on average, $87 \%$ of their time indoors, $7 \%$ in enclosed transit and $6 \%$ outdoors. At least $62 \%$ of the population over 11 years of age and $46 \%$ of non-smokers are near others tobacco smoke at some time during the day [1].

Massey et al showed that the outdoor sources as well as indoor activities influenced the coarse and specially the fine particulate matter concentrations of indoors in houses located in different microenvironments in all the seasons. The study was based upon the data generated from sampling, questionnaire diary entries and survey of houses [2].

Energy consumption of households basically depends on environmental and human factors. Human factors are related to the user influence like the number of occupants, the length of occupancy in the home and other aspects such as people with special heat demand (like babies or old people) and the user behaviour such as temperature choice or ventilation behaviour [3]. The indoor environment is a complex system including factors like thermal, visual and acoustic conditions, indoor air quality, electromagnetic fields, static electricity and vibration. The influence of these factors on human beings has been studied extensively and for several of these factors guidelines for design and measurements have been established [4]. Availability of controls and their appropriate use is a key to better performance of the building and for improving occupant satisfaction. Opening of windows and drawing of blinds or curtains are the most extensively used activity. The proportion of windows open and blinds/curtains drawn increased with an increase in indoor or outdoor instantaneous temperatures. The study shows that blinds/curtains are fully 
drawn or half-drawn in about $24 \%$ of the responses and 'window open' for $62 \%$ of the responses [5].

The need to analyse and understand energy consumption in relation to household's activity patterns, it is vital for developing policy means that contribute to an energy efficient life and what people would deem as a "good" everyday life. To do this we need to learn more about how energy use is a part of everyday life. By utilising many time diaries from a population we can also discover differences in activity patterns for example between men and women, single households and families, adults and children. We can also visualise activity patterns in a household during a period and, through that, discuss and analyse consequences for energy consumption [6].

The indoor environment is an influential factor to environmental quality. People spend a majority of their time in buildings, the average western person spends up to $85 \%$ of their life in a building, or in a vehicle conveying them from one building to another [4]. The housing environment is the main setting for many; consequently certain conditions of this environment can have a profound effect on the quality of the environment and the public's health. Studies have highlighted that at present many people live in conditions that are considered 'unhealthy' because of high levels of mould growth, damp and dust mite concentrations. Approximately $20 \%$ of all dwellings in England suffer from mould growth and dampness to some degree [7]. While reduction in the rate of fresh air was regarded very effective in minimising both heating and cooling loads, it was considered necessary to maintain clean air in the occupied space and hence that people can work without any health hazards. The government of Japan took an initiative to set up energy conservation guidelines for commercial buildings in 1978 where the threshold value of $\mathrm{CO}_{2}$ concentration in occupied spaces was to be determined in view of controlling fresh air load. Hot discussion was made among scientists and engineers whether or not the $\mathrm{CO}_{2}$, concentration must be maintained lower than 1000 ppm as specified in the Law on the Assurance of Healthy Conditions in Buildings [8].

On the one hand, architects and all building design professionals have a bigger mission of designing new sustainable buildings while today the building industry is facing a new challenge where "refurbishment becomes the challenge for future architects". Refurbishment option could be seen as more modest and simple at the first glance referring to demolition and new development, but the results of improvement of energy performance of dwelling housing in Belgrade showed efficiency in energy savings and $\mathrm{CO}_{2}$ reductions, as well as improved housing quality. By improving thermal insulation and replacing windows, the contribution to energy savings and improvement of the building appearance are achieved [9].

This study has been undertaken as part of the Energy Innovation for Deprived Communities (EIDC) project, which aims to deliver a new approach to energy efficiency and renewable energy projects within a minimum of ten of the most deprived communities across six Local Authorities within Yorkshire and the Humber region in the UK. The properties will be assessed by energy efficiency experts and then brought up to modern standards with a range of measures including so-called smart electricity meters and heating systems upgrades to change of boilers, wall and loft insulations, double glazing, insulated cladding and even solar panels where appropriate. It is important for the success of the EIDC project that both detailed monitoring and post occupancy evaluation are performed on a sample of houses before rolling out a wider refurbishment. This study aims to investigate indoor environment of homes in Kirklees, Yorkshire, UK, before refurbishment and to correlate this to the energy consumption. In addition, in the study, the indoor activity with respect to energy consumption and ventilation has been investigated.

\section{METHODOLOGY}

Indoor air temperatures and relative humidity levels were measured at the dwelling using HOBO U12-012 and U10-003 data loggers. Indoor carbon dioxide levels were also recorded in the two pre-refurbished homes using Telaire $7001 \mathrm{CO}_{2}$ meters. Although $\mathrm{CO}_{2}$ is not toxic, it is commonly used as an indicator of air quality and the high levels of $\mathrm{CO}_{2}$ indicate inadequate ventilation in a living space, which also relates to the indoor air quality (IAQ).

All HOBO U12-012 data loggers and $\mathrm{CO}_{2}$ meter were placed in the living room, specifically in the breathing zone of a person sitting on a sofa (approximately 1.5 metre above the floor) and away from open windows. In addition, participants were requested to behave as normal within their home during the monitoring period in order to obtain realistic data. HOBO U10-003 data loggers were placed in the bedroom. The objectives of monitoring indoor air quality were to gain an insight into conditions within residents' homes and to compare indoor environmental conditions i.e. air temperature $\left({ }^{\circ} \mathrm{C}\right)$, relative humidity $(\mathrm{RH} \%)$, and carbon dioxide $\left(\mathrm{CO}_{2}\right)$ to accepted standard guidelines. Average levels of each variable were collected in 15-minute intervals over a 24-hour period for the periods of two weeks. Electrical energy consumption was collected via installed smart meters (iMeter from ISA). It comes with communication system that enables meter readings to be taken at any time of the night or day without the need for a visit from a meter reader. This smart meter technology automatically sends the reading information electronically via broadband connection to an online secure server. Participant completed an indoor log sheet, recording the approximate time of certain behaviours known to affect the indoor environment, including smoking, cooking, opening windows, etc. Table 1 shows a sample of one day of indoor activity and the number of occupants involved in each activity. 
TABLE 1

DAILY INDOOR ACTIVITY LOG SHEET

\begin{tabular}{lcc}
\hline \hline Activity & $\begin{array}{c}\text { Time span (e.g. } \\
\text { 8:00am - 8:30am) }\end{array}$ & $\begin{array}{c}\text { Number of people in } \\
\text { home during this activity }\end{array}$ \\
\hline First person gets up & $7: 15 \mathrm{am}$ & 4 \\
\hline $\begin{array}{l}\text { Period when breakfast } \\
\text { being prepared (and was } \\
\text { a cooker used?) }\end{array}$ & $\begin{array}{c}\text { 9:00am - 10:00am } \\
\text { No }\end{array}$ & 4 \\
\hline $\begin{array}{l}\text { Period(s) when home } \\
\text { empty during day } \\
\text { (please list) }\end{array}$ & $\begin{array}{c}\text { 11:00am - } \\
\text { 16:00pm }\end{array}$ \\
\hline $\begin{array}{l}\text { Period when lunch being } \\
\text { prepared (and was a } \\
\text { cooker used?) }\end{array}$ & \\
\hline $\begin{array}{l}\text { Period when dinner } \\
\text { being prepared (and was } \\
\text { a cooker used?) }\end{array}$ & $\begin{array}{c}\text { 17:00pm - } \\
\text { Yes }\end{array}$ \\
\hline $\begin{array}{l}\text { Period when other meals } \\
\text { or snacks prepared ( and } \\
\text { was a cooker used?) }\end{array}$ & \\
\hline $\begin{array}{l}\text { Periods when windows } \\
\text { are open (please list) }\end{array}$ & \\
\hline $\begin{array}{l}\text { Periods when doors are } \\
\text { open (please list) }\end{array}$ & $\begin{array}{l}\text { 18:00pm - } \\
\text { 19:00pm }\end{array}$ \\
\hline $\begin{array}{l}\text { Period when showers or } \\
\text { baths were taken }\end{array}$ & 9:00am - 10:00am \\
\hline \begin{tabular}{l} 
Last person goes to bed \\
\hline \hline
\end{tabular} & 11:15pm & 4 \\
\hline
\end{tabular}

Table 2 describes the home condition, home type, home age, and ventilation condition of one house as a pilot study within Kirklees area.

TABLE 2

GENERAL DESCRIPTION OF HOME LOCATED IN KIRKLEES

\begin{tabular}{lc}
\hline \hline Description & Dwelling K1 \\
\hline Type of building & Semi-detached \\
\hline Home age (yr) & 65 \\
\hline Dwelling - tenure & Rented \\
\hline Window type & Fully double glazed \\
\hline Ventilation & Natural -at least one window open every day \\
\hline Cooker type & electric \\
\hline Shower type & electric \\
\hline No. of occupants and ages & $4(67,65,38$ and 37 years $)$ \\
\hline Description & Dwelling K1 \\
\hline \hline
\end{tabular}

\section{RESULTS AND DISCUSSION}

The data were collected from the indoor monitoring equipment and statistically analysed to investigate the indoor thermal condition and air quality in a home which was chosen as a pilot study. Temperature and relative humidity levels within an indoor environment will vary within the time of year and physical indoor environment. However, the concentration of airborne fungal spores and bacteria is related to room temperatures [10]. In general, it would be reasonable to maintain a temperature of around $22-23^{\circ} \mathrm{C}$ within living room and form $17-19^{\circ} \mathrm{C}$ in bedroom [11].

The results have been compared to published standard guidelines. The daily mean indoor air temperature $\left({ }^{\circ} \mathrm{C}\right)$ of the living room and the bedroom for one week (15/09/2011 to 20/09/2011) did not comply with the CIBSE recommendation for the range of internal temperatures $\left(22-23^{\circ} \mathrm{C}\right)$ in living rooms and comply for the standard guideline of internal temperatures $\left(17-19^{\circ} \mathrm{C}\right)$ in the bedroom. On the other hand, the optimum level of humidity should be between $40-70 \%$ [11]. The average relative humidity $\mathrm{RH} \%$ for the living room and the bedroom do agree with the standard guidelines. Moreover, carbon dioxide $\left(\mathrm{CO}_{2}\right)$ is present in the natural environment, being produced by combustion of biological processes. Carbon dioxide is present at typical levels of about 360ppm in the ambient urban environment though this can rise substantially inside occupied buildings. Currently, there are no UK $\mathrm{CO}_{2}$ standards for indoor air, although the American Society of Heating, Refrigerating and Air Conditioning Engineers (ASHRAE) guidance recommends that carbon dioxide levels should not exceed 1000ppm inside a space [12]. However, carbon dioxide levels are often used as a guide to whether or not a space has a sufficient quantity of fresh air. The average indoor $\mathrm{CO}_{2}$ levels were measured during the autumn season 2011 and the results showed that the indoor $\mathrm{CO}_{2}$ levels of the living room for one week fluctuating around the recommended value of 1000ppm for indoor space.

Figure 1 shows the daily indoor air temperature $\left({ }^{\circ} \mathrm{C}\right)$ of the living room. The temperature in the living room is fluctuating above $22^{\circ} \mathrm{C}$. In comparison with the standard guidelines it is clear that the living room did comply with the CIBSE recommendation for the range of internal temperatures (22$23^{\circ} \mathrm{C}$ ) in living room. The same figure shows the levels of $\mathrm{CO}_{2}$ is under the recommended value most of the time with some peaks above it (see Figure 1).

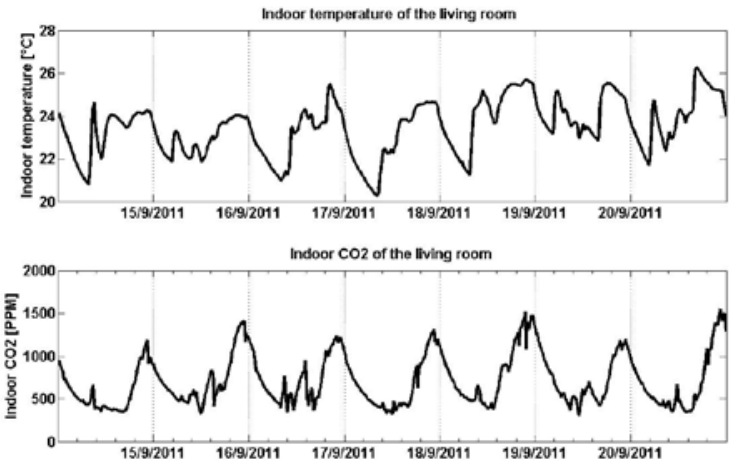

Fig. 1. Indoor temperature and $\mathrm{CO}_{2}$ of the living room.

Figure 2 shows the frequency distribution of different temperature values occurred per week within the living room. The living room have the value of $24^{\circ} \mathrm{C}$ which is the most often occurred value per week. The question is why $24^{\circ} \mathrm{C}$ is the most often occurred value in the living room? And how temperature changes when another variable such as electric power consumption does?. To answer those questions, the log sheet for indoor activity should be analysed with its corresponding time series and period. 


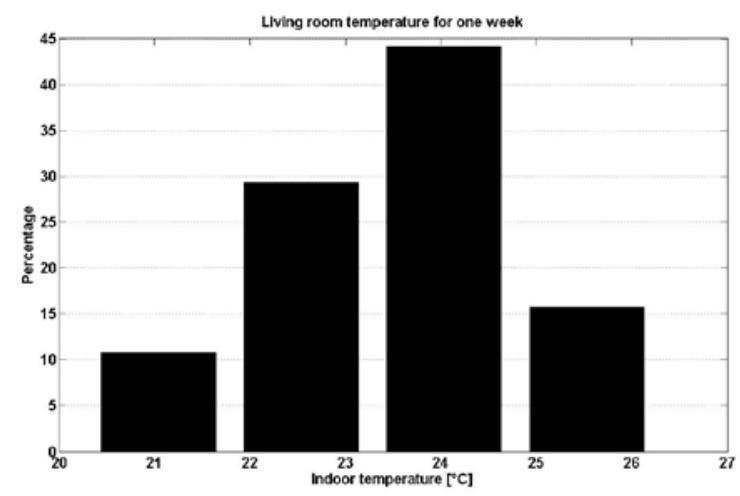

Fig. 2. Percentage of temperature for living room during one week.

In the study, one week (15/09/2011 to 20/09/2011) was chosen to plot indoor temperature against electrical energy consumption for that week. Figure 3 shows that the electrical energy consumption increased in the evening for everyday as well as the temperatures increased in the evening for everyday and remained on that level till 22:00pm due the lack of ventilation during the time. The reason for that heat to rise up is due to casual heat gains which are given off by various activities and equipment in the building. The major sources of such heat are the heat generated from lighting, machinery, refrigerators and electrical appliances [13]. Furthermore, the indoor activity log sheet was checked against Figure 1 for that week (15/09/2011-20/09/2011) and it was found that the reason why the electrical energy consumption was rising in the evening due to using the electric cooker for dinner time and the shower was used after dinner and the number of occupants in that activity was four.
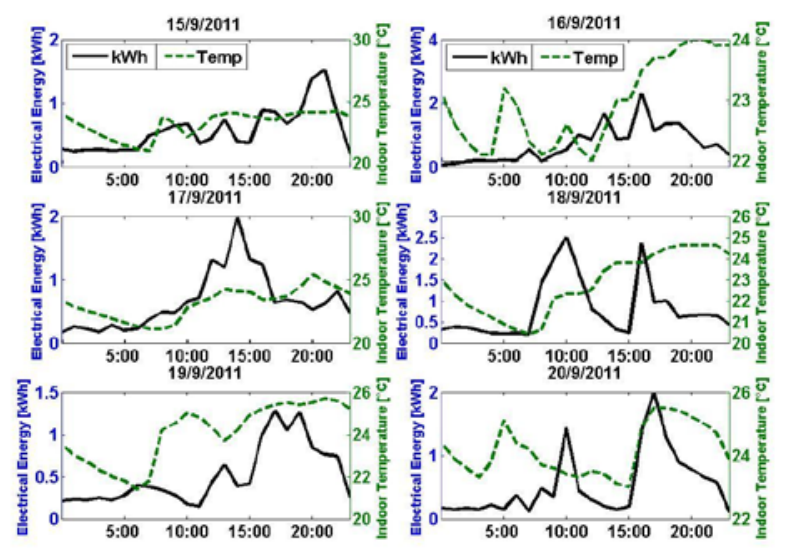

Fig. 3. Indoor temperature and electrical energy use for one week.

Figure 4 shows the indoor $\mathrm{CO}_{2}$ levels for each day of the week (15/09/2011 to 20/09/2011) plotted against the electrical energy consumption to investigate their daily changes and the effects of indoor behaviour on them. Carbon dioxide level is sometimes above 1000ppm especially in the evening and as can be seen from Figure 2 that the indoor $\mathrm{CO}_{2}$ levels followed a pattern in the two homes. Levels were seen to be under $1000 \mathrm{ppm}$ during early morning and day time, later rising at evening and night time due to the increase of human activity and the lack of ventilation for all the days. The daily indoor activity log sheet was checked for the ventilation behaviour and it was found that the windows and door are opened during the day time and are closed during the evening till the following day. Electrical energy consumption also increases in the evening for couple of hours and then goes down again.

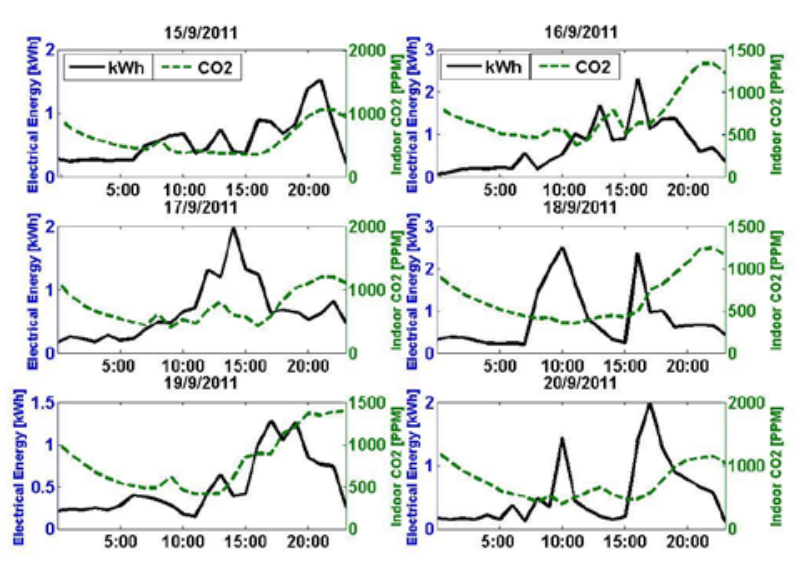

Fig. 4. Indoor $\mathrm{CO}_{2}$ and electrical energy use for one week.

Daily indoor air temperatures and daily $\mathrm{CO}_{2}$ levels were correlated with the electrical energy consumption, and it was found that statistically significant results as shown in Table 3.

TABLE 3

CORRELATION RESULTS OF DAILY TEMPERATURE AND $\mathrm{CO}_{2}$ AGAINST ELECTRIC ENERGY CONSUPMTOIN

\begin{tabular}{lccc}
\hline \hline Date & $\begin{array}{c}\text { Correlation value } \\
\text { (elec. vs. temp.) }\end{array}$ & $\begin{array}{c}\text { Correlation value } \\
\left.\text { (elec. vs. } \mathrm{CO}_{2}\right)\end{array}$ & $\begin{array}{c}\text { Correlation value } \\
\left(\mathrm{CO}_{2} \text { vs. temp.) }\right.\end{array}$ \\
\hline $15 / 09 / 2011$ & 0.47 & 0.3678 & 0.4085 \\
\hline $16 / 09 / 2011$ & 0.37 & 0.0726 & 0.7823 \\
\hline $17 / 09 / 2011$ & 0.50 & -0.1297 & 0.6632 \\
\hline $18 / 09 / 2011$ & 0.075 & -0.3088 & 0.6199 \\
\hline $19 / 09 / 2011$ & 0.57 & 0.5067 & 0.5767 \\
\hline $20 / 09 / 2011$ & 0.56 & -0.1755 & 0.3722 \\
\hline \hline
\end{tabular}

Figure 5 shows this direct (positive) relation. The results indicated that the higher the energy use the warmer the dwelling gets due to the casual heat gains from lighting and electrical appliances [13]. Figure 6 indicated that sometimes the $\mathrm{CO}_{2}$ level has positive relation and sometimes has negative relation with the electrical energy consumption.
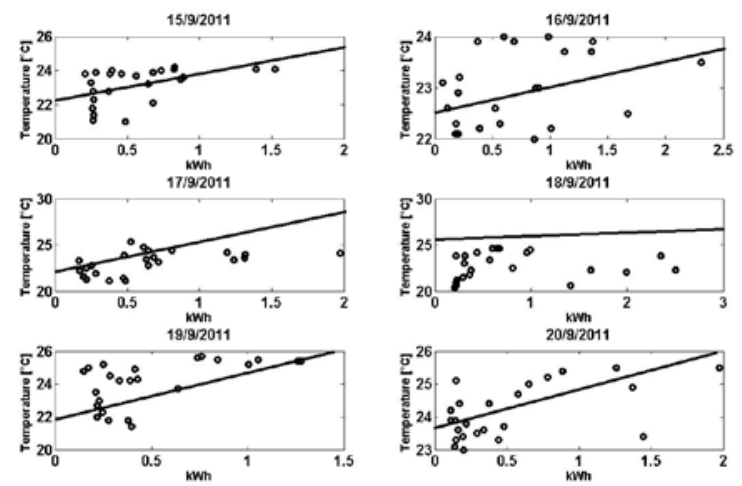

Fig. 5. Correlation of daily temperature and electrical energy consumption. 

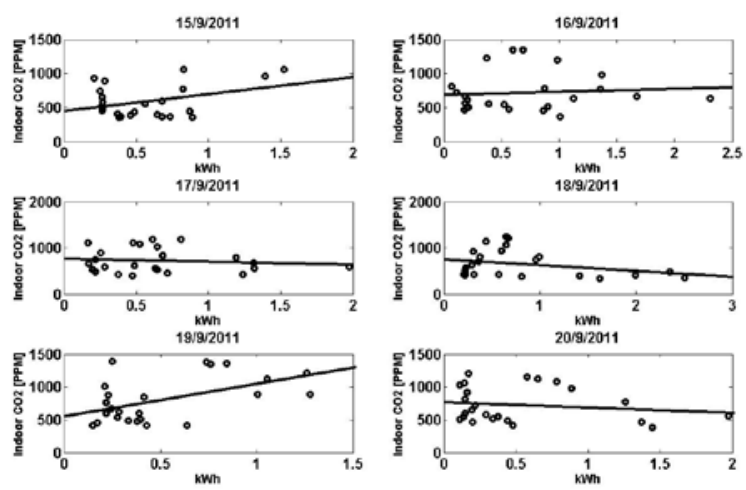

Fig. 6. Correlation of daily $\mathrm{CO}_{2}$ and electric energy consumption.

Daily indoor air temperature and daily $\mathrm{CO}_{2}$ were correlated with statistically significant results for everyday as shown in Table 3. Figure 7 shows this direct (positive) relation. The results may indicate that the warmer space has lack of air ventilation rates and therefore, the $\mathrm{CO}_{2}$ levels are higher, and it also reflects the dilemma of achieving proper ventilation and indoor thermal comfort.
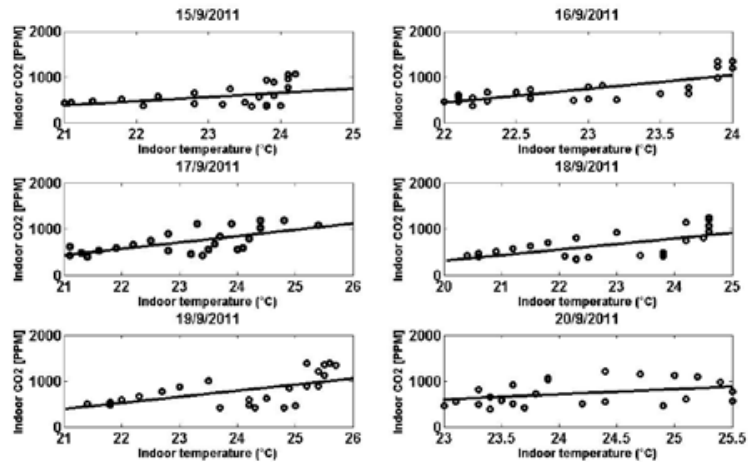

Fig. 7. Correlation of daily $\mathrm{CO}_{2}$ and daily indoor temperature.

\section{CONCLUSIONS}

$\mathrm{U}$ This study aimed to analyse the daily pattern of indoor environment and energy consumption by analysing an indoor log sheet, recording the approximate time of certain behaviours known to affect the indoor environment and energy consumption, including smoking, cooking, opening windows, etc. By relating the data from the indoor log sheet to the time series of temperature and energy consumption it was found that the energy consumption rises in the evening due to the use of cooker to prepare dinner and the use of electric shower. In addition, the temperatures increased in the evening for everyday and stayed on that level till late night due the lack of ventilation during the time. There was a direct relation between the temperature and the energy consumption. The results indicated that the higher the energy use the warmer the dwelling gets due to the casual heat gains from lighting and electrical appliances. In addition, there was a proportional relation between indoor temperature and $\mathrm{CO}_{2}$ levels which reflected the dilemma of achieving proper ventilation and indoor thermal comfort.

\section{ACKNOWLEDGMENT}

This paper is the result of the work undertaken as part of the BIG Energy Upgrade Programme (BEU). The project has attracted $£ 7.0$ million from the European Regional Development Fund through the Yorkshire and the Humber ERDF Programme 2007-13.

\section{REFERENCES}

[1] P. L Jenkins, T. J. Phillips, E. J. Mulberg and S. P. Hui, "Activity Patterns of Californians: Use of and Proximity to Indoor Pollutant Sources”, Atmospheric Environment, Vol. 26A, No. 12, 1992, pp. 21412148.

[2] D. Massey, A. Kulshrestha, J. Masih, A. Taneja, "Seasonal Trends of $\mathrm{PM}_{10}, \mathrm{PM}_{5.0}, \mathrm{PM}_{2.5} \& \mathrm{PM}_{1.0}$ in Indoor and Outdoor Environments of Residential Homes Located in North-Central India”, Building and Environment, Vol. 47, 2012, pp. 223-231.

[3] P. S. P. Cadima, "Retrofitting Homes for Better Energy Performance: The Occupant's Perspective”, in PLEA 2009 - 26th Conference on Passive and Low Energy Architecture, Quebec City, Canada, 22-24 June 2009.

[4] B. W. Olesen and J. Seelen, "Indoor Climate Criteria for a Comfortable Indoor Environment in Buildings", Journal of Thermal Biology, Vol. 18, No. 5/6, 1993, pp. 545-549.

[5] I. A. Raja, J. F. Nicol, K. J. McCartney, M. A. Humphreys, "Thermal Comfort: Use of Controls in Naturally Ventilated Buildings", Energy and Buildings, Vol. 33, 2001, pp. 235-244.

[6] K. Ellegard, J. Palm, "Visualizing Energy Consumption Activities as a Tool for Making Everyday Life More Sustainable”, Applied Energy, Vol. 88, 2011, pp. 1920-1926.

[7] T. Oreszczyn, and S. Pretlove, Mould Index', in J. Rudge and F. Nicol, (2000), Cutting the Cost of Cold, E \& FN Spoon: London, pp. 122-133.

[8] K. Kimura, "Relationship between Energy Conservation in Buildings and Indoor Air Quality”, Journal of Thermal Biology, Vol. 18, No. 5/6, 1993, pp. 541-543.

[9] B. Stein, "Refurbishment as Challenge for Future Architects", in the Oxford Conference 2008, Oxford, UK.

[10] I. Goh, J. P. Obbard, S. Viswanathan, Y. Huang, "Airborne Bacteria and Fungal Spores in the Indoor Environment: A Case Study in Singapore”, Acta Biotechnologica, 2000, pp. 67-73.

[11] CIBSE, Environmental Design CIBSE Guide A, Chartered Institution of Building Services Engineers, London, 2006.

[12] American Society of Heating, Refrigerating and Air Conditioning Engineers (ASHRAE), Available: http://www.ashrae.org/, 2013.

[13] R. McMullan, "Environmental Science in Building”, Palgrave, (5th ed.), 2002. 


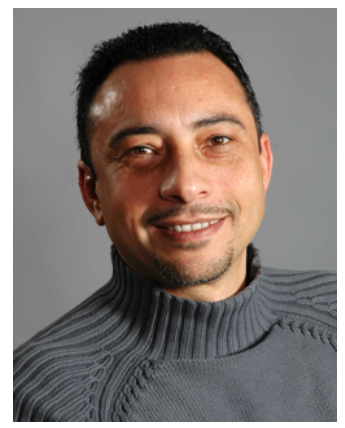

Dr. Mohamed Refaee (BSc, MSc, PhD) Dr. Refaee is Senior Research Fellow in the School of Architecture, Building Environments Analysis Unit (BEAU) Research Centre at the University of Sheffield. He is involved in a major £14.9 million ERDF project (The BIG Energy Upgrade: Energy Innovation for Deprived Communities) investigating ways to improve living in homes and energy consumption. He also involved in an EPSRC project (VivaCity 2020, Sustainable Urban Environments) investigating indoor environments. He completed his $\mathrm{PhD}$ at the University of Central Lancashire (UCLAN), UK in the area of Biomedical Engineering. He received his Master degree from University of East London, UK in Electronics and Control Systems and BSc in Electrical Power Machine from Egypt.

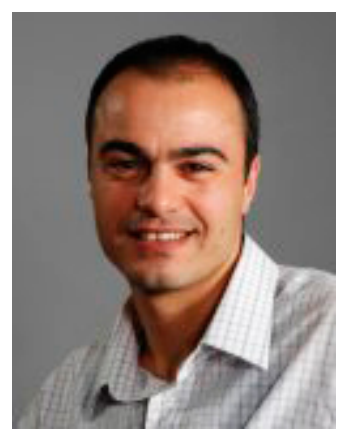

Dr. Haşim Altan (DipArch, MArch, PhD, PGCE, FHEA, CEng) Dr Altan is Lecturer in Sustainable Environmental Design and Director of Building Environments Analysis Unit (BEAU) Research Centre in the School of Architecture at the University of Sheffield. He is a Chartered Architect (RIBA) and a Chartered Engineer (CIBSE) with over 15 years of experience in the field of Sustainable Environmental Building Design. Dr. Altan has focused on building environmental sustanability in his research and worked extensively on energy efficiency strategies for buildings through large research consortiums funded by RCUK and EU platforms. He has taught courses and run workshops in Environmental Design in various universities in the UK, Republic of Ireland, Czech Republic and Turkey. 